\title{
MOEDA ÚNICA NO MERCOSUL: POSSIBILIDADES E LIMITES ${ }^{1}$
}

\author{
Roberto Santolin ${ }^{2}$ \\ Rosa Fontes ${ }^{3}$
}

Resumo - O presente trabalho teve por objetivo apresentar os aspectos teóricos e práticos de uma unificação monetária entre Brasil e Argentina, com base no conceito de Área Monetária Ótima (AMO). Com esse fim, foram analisados os comportamentos dos indicadores macroeconômicos de dívida total, déficit público, taxas de juros e taxas de inflação entre Brasil e Argentina. Foram ainda realizadas análises de simetria dos ciclos econômicos entre os dois países. Os indicadores se mostraram divergentes, possivelmente pelas diferentes políticas monetárias e cambiais adotadas por Brasil e Argentina durante toda a década de 1990. As análises de integração comercial entre os dois países apontaram um baixo nível de integração comercial. Os dados também indicaram um afastamento, desde 1998, da tendência de formação de uma área monetária entre os dois países. Em outras palavras, no curto prazo prevalecem custos elevados e baixos benefícios associados a uma única moeda no Mercado Comum do Sul (Mercosul).

Palavras-chave: Mercosul, Macroeconomia Aberta, União Monetária, Áreas Monetárias Ótimas.

\section{Introdução}

\subsection{O problema e a sua importância}

Depreende-se da literatura econômica que são indiscutíveis os ganhos do comércio internacional e da integração econômica. Esse fato tem sido fortalecido pelo sucesso da União Européia (UE) desde a sua criação,

\footnotetext{
1 Os autores agradecem as contribuições anônimas do corpo editorial da revista, eximindo-os, obviamente, de qualquer erro remanescente. Recebido em 10/05/2005 Aceito em 30/06/2005.

2 Mestrando em Economia Aplicada pela Universidade Federal de Viçosa.

3 Ph.D. em Economia pela NCSU-USA, Professora Titular do Departamento de Economia da Universidade Federal de Viçosa e pesquisadora do CNPq.
} 
em 1957, com o Tratado de Roma. Após 45 anos, a UE conquista o objetivo final de uma União Econômica, qual seja a unificação monetária. Essa vitória, porém, foi marcada ao longo dos anos por diversas dificuldades, no que diz respeito às políticas adotadas, que, por vezes, geraram custos sociais de curto prazo elevados.

Com a intenção de eliminar barreiras ao comércio e adotar uma tarifa externa comum surgiu em 1991, com o Tratado de Assunção, o Mercado Comum do Sul, formado por Brasil, Argentina, Uruguai e Paraguai. Desde a sua criação, o Mercosul tem procurado alcançar os objetivos acordados, conquistando, sobretudo, um grande aumento nas relações comerciais entre os países associados.

A intensificação da integração comercial e o sucesso inicial dos programas de estabilização na Argentina e no Brasil motivaram a elaboração de diferentes propostas, apontando que a integração produziria, no limite, uma unificação monetária entre os países membros do Mercosul (Giambiagi; Rigolon, 1999).

A adoção de uma moeda única por parte de uma região ou bloco é associada, na literatura de Macroeconomia Aberta ou Economia Monetária Internacional, ao termo Área Monetária Ótima (AMO). Assim, o problema a ser analisado consiste em verificar a possibilidade da união monetária entre Brasil e Argentina, principais países membros do Mercosul. O resultado deste trabalho será o levantamento dos atuais benefícios e custos de curto prazo associado à unificação econômica. Além disso, a presente pesquisa procurou verificar a existência de uma tendência de formação de AMO entre Brasil e Argentina.

O objetivo, portanto, do presente trabalho foi apresentar os aspectos teóricos de uma união monetária e sua aplicação prática ao Mercosul, segundo as hipóteses de uma AMO. Apesar de saber que o bloco é ainda uma união aduaneira parcial, com dificuldades para estabelecer um livre comércio e uma tarifa externa comum, pretendeu-se investigar as condições econômicas atualmente existentes que favoreceriam ou não uma união monetária futura entre os países membros no longo prazo. 
Mais especificamente, pretendeu-se: (i) analisar as políticas econômicas realizadas pelo Brasil e pela Argentina e seus impactos no Mercosul; (ii) realizar uma análise da simetria dos ciclos econômicos dentro do Mercosul, observando-se as variações dos níveis de produção interna de cada país; e (iii) analisar benefícios e custos de uma atual unificação monetária.

A próxima seção apresenta uma revisão de literatura sobre $\mathrm{AMO}$, seus benefícios e custos e as condições que possibilitam sua formação no Mercosul. A seção 3 apresenta a metodologia e fonte de dados. Em seguida, têm-se os resultados e discussão e, por último, a conclusão.

\section{Revisão da literatura}

\section{1. Áreas Monetárias Ótimas}

O termo Área Monetária Ótima (AMO) foi utilizado pela primeira vez no trabalho de seminal de Mundell (1961). Segundo ele, uma AMO seria uma forma de se aumentar a eficácia dos regimes cambiais. Como ilustração, ele utilizou um exemplo hipotético, no qual se têm duas regiões ou países, denominados A e B, com fronteiras geográficas, cada um deles especializado na produção de um bem. Na hipótese de um deslocamento da demanda de produtos da região $\mathrm{B}$ para a região A haverá uma tendência de aumentar o desemprego em B e a inflação em A. Com salários nominais rígidos, verificou-se que os movimentos na taxa de câmbio podem ser usados para alterar os salários reais e restaurar o nível de preços, do emprego e do balanço de pagamentos. Uma suposta desvalorização cambial na região B e uma valorização em A eliminaria o desemprego em B e a inflação em A. No entanto, se A e B têm fortes ligações comerciais, uma pequena redução nos preços de $\mathrm{B}$ levaria a um aumento na demanda pelos produtos de B. Então, o pleno emprego poderia ser restabelecido rapidamente se os mercados de trabalho e de capital das duas regiões fossem muito relacionados. Os trabalhadores desempregados poderiam facilmente mover-se de B para A, a fim de encontrar trabalho, e o capital de A poderia ser utilizado de modo mais 
lucrativo em B. A capacidade dos fatores em migrar para o estrangeiro reduziria a severidade do desemprego do país B e a taxa de retorno disponível para os investidores em A. Nesse contexto, não haveria razão para um regime de câmbio flexível entre os dois países. Seria mais vantajoso que as duas economias mantivessem um câmbio fixo ou, em situação extrema, uma moeda única, criando-se uma única região monetária. Esse conceito foi definido por Mundell como Área Monetária Ótima (AMO).

Uma unificação monetária bem-sucedida depende, antes de tudo, da qualidade da moeda. Como ressaltaram Giambiagi e Rigolon (1999), a busca da convergência dos indicadores macroeconômicos, entre países que pretendem unificar suas moedas, é necessário quando o objetivo é a criação de condições para que a moeda tenha valor, ou seja, que cumpra as funções de meio de troca, de reserva de valor e de unidade de conta.

Nesse sentido, o Tratado de Maastricht ${ }^{4}$ delimitou os parâmetros necessários para uma unificação bem-sucedida. O Tratado de Maastricht especificava que os países membros necessitavam atingir os seguintes critérios de convergência macroeconômica: (i) a taxa de inflação do país poderia ser no máximo $1,5 \%$ maior que a média dos três países membros de menor inflação; (ii) o país precisaria manter uma taxa de câmbio estável dentro do mecanismo europeu, sem desvalorizar por sua própria iniciativa; (iii) o país poderia ter um déficit do setor público de no máximo $3 \%$ de seu PIB (exceto em condições temporárias ou excepcionais); e (iv) o país poderia ter uma dívida pública inferior ou próxima a um nível de referência de $60 \%$ de seu PIB.

Segundo Eichengreen (1998), é óbvio que se uma AMO é afetada de modo igual pelos choques não há vantagens em alterar os preços relativos entre seus países-membros. No que diz respeito aos países membros com maiores taxas de desemprego, a livre mobilidade da mão-de-obra

Na Europa, em 10 de dezembro de 1991, os líderes dos países da União Européia reuniram-se na cidade de Maastricht, Holanda, para firmar um acordo que propunha a ratificação nacional de emendas de amplo alcance ao Tratado de Roma. 
eliminaria facilmente o problema, tornando-se ótimo dispensar o principal instrumento usado para modificar os preços relativos, ou seja, as mudanças na taxa de câmbio e usufruir os benefícios da moeda única.

Frankel (1999) observou que, quanto maior o grau de correlação entre os ciclos econômicos desses países, menor a necessidade de se coordenar a política monetária. Dessa forma, ele sugeriu como critério de identificação de uma AMO que as regiões ou países apresentem alto coeficiente de correlação entre as séries de nível de atividade.

A simetria de ciclos econômicos entre países propensos a formar uma AMO tende a levar também à simetria das taxas de câmbio. Essa afirmativa é respaldada na idéia de que economias extremamente integradas comercialmente e com mobilidade de fatores passariam por crises correspondentes. Nessa óptica, uma queda de demanda interna no país doméstico que gerasse uma queda nos níveis de preços faria com que mecanismos de oferta e demanda dentro de uma AMO restabelecessem o equilíbrio, promovendo a simetria dos ciclos que formam a área. Portanto, uma simetria de ciclos econômicos tornaria as taxas de câmbio ineficazes como instrumentos de ajuste entre economias.

\subsubsection{Benefícios e Custos de uma AMO}

Segundo Krugman e Obstfeld (2000), taxas flexíveis de câmbio são capazes de abrandar os choques econômicos e, ao mesmo tempo, tornam os preços relativos mais imprevisíveis, impedindo que o governo interfira na taxa de inflação. Para ponderar os custos econômicos de se unir um grupo de países com taxas de câmbio mutuamente fixas, verificou-se a perda da autonomia das políticas de estabilização que um país sacrifica e seu conseqüente ganho de eficiência e credibilidade.

Um benefício adquirido com a formação de uma AMO está na simplificação dos cálculos econômicos. O câmbio fixo possibilita uma base mais previsível de decisões que envolvem transações internacionais 
do que as taxas flutuantes. Assim, ele aumenta o ganho de eficiência monetária, passando a evitar a incerteza, a confusão de cálculo e os custos de transação que surgem quando as taxas de câmbio flutuam. É difícil colocar em números o ganho de eficiência obtido, mas é certo que, quanto maior o tamanho da área, maior o ganho. Além disso, a união monetária aumenta a credibilidade da política monetária e reduz o viés inflacionário das políticas domésticas. Dada a rigidez de preços e salários, os Bancos Centrais têm incentivos em promover surpresas inflacionárias para aumentar o nível de atividade, financiar déficits orçamentários, equilibrar o balanço de pagamentos ou amortizar a dívida pública. Entretanto, como os agentes econômicos antecipam esses incentivos, as políticas freqüentemente produzem apenas um viés inflacionário. Já em uma união monetária, o incentivo do Banco Central unificado em recorrer à inflação como instrumento de política é estritamente menor do que o da maioria dos Bancos Centrais nacionais, o que beneficia os países membros com histórico de inflação mais elevada. Em outras palavras, a união monetária "amarra as mãos" dos policymakers e permite que eles "importem" credibilidade do país com maior reputação antiinflacionária (Giavazzi; Pagano, 1988).

A conclusão a que se chega é que um alto grau de integração econômica entre um país e uma área de taxa de câmbio fixa amplia o grau de eficiência monetária, quando esse país fixa sua taxa de câmbio com as moedas da área. Quanto mais amplos forem os movimentos comerciais entre as fronteiras, maior será o ganho decorrente de uma taxa de câmbio fixa. Entretanto, ser membro de uma área de taxa de câmbio fixa pode envolver custos, mesmo quando a inflação da área é baixa. Os países que ingressam numa área de câmbio fixa perdem a capacidade de usar suas políticas monetária e cambial domésticas para responder aos efeitos de choques no produto, na inflação e no balanço de pagamentos. A magnitude dos custos depende da natureza dos choques, da disponibilidade de instrumentos alternativos de ajuste e do grau de abertura das economias.

Nesse contexto, na possibilidade de uma queda de demanda em um país da área, dado que a moeda permanece estável em relação às moedas 
dos outros países, a economia volta ao pleno emprego após um período de recessão, durante o qual os preços dos produtos e os salários dos trabalhadores caem. Porém, a severidade dessa retração depende do nível de integração do país com o bloco. Quanto maior a integração, menor a queda e, portanto, menos dispendioso o ajuste da economia. Se a estabilidade macroeconômica adicional que o país obtém, por meio de uma taxa de câmbio fixa, é pequena, então, convém que o país mantenha sua taxa de câmbio flexível, em vez de se unir à área monetária.

\subsection{Integração Financeira do Mercosul}

A mobilidade de capital é um dos requisitos necessários à formação de uma AMO. No Mercosul, tarefas destinadas a promover o avanço do processo de integração financeira no Mercosul estão a cargo do Subgrupo de Trabalho $\mathrm{N}^{\circ} 4$ - Assuntos Financeiros (SGT-4), integrado pelos Bancos Centrais dos Estados Partes.

O SGT-4 tem como finalidade o desenvolvimento de estudos e sugestões de medidas que contribuam para a criação de um mercado comum regional na área financeira, contemplando os setores bancário, de seguros e de mercado de capitais. Seu programa de trabalho está orientado em duas linhas de ação básicas e complementares: (i) a harmonização das normas que regem o funcionamento dos sistemas financeiros dos países do Mercosul, como forma de se obter um nível adequado de solidez e transparência; e (ii) a liberalização progressiva dos serviços bancários e financeiros, dentro dos parâmetros constitucionais.

Do ponto de vista quantitativo, como afirmou BID-INTAL (1996), os investimentos intra-Mercosul representam uma quantia bem menor do que a extrazona. No entanto, a cooperação e os fluxos de investimento no bloco adquiriram um dinamismo notável. Um levantamento realizado em maio de 1996 identificava um total de 313 empreendimentos conjuntos argentino-brasileiros, dos quais $60 \%$ estavam vinculados ao setor produtor de bens. Segundo a mesma fonte, $44 \%$ do total tem impacto produtivo 
direto. Se esses resultados são comparados com um levantamento similar realizado em fins de 1992, constatou-se que o número total de empreendimentos triplicou em um período de pouco mais de três anos.

Os países do Mercosul, como outros mercados emergentes, passaram por uma etapa de forte restrição financeira nos anos de 1980, a partir da crise da dívida externa mexicana de 1982, que rapidamente se difundiu para os outros países. Na década de 1990, esses países viveram a situação inversa de forte disponibilidade de recursos de origem externa. Essa fase compreendeu tanto capitais de portfólio de alta volatilidade relativa quanto um crescente investimento direto estrangeiro, ligado em parte a processos de privatização de empresas dos estados nacionais (Lavagna, 2003).

Machado (1997), no entanto, afirmou que a mobilidade de capital entre esses países é inexpressiva e distingue alguns pontos para a consolidação da integração financeira do Mercosul: (i) harmonização da legislação tributária sobre a circulação de capitais e operações financeiras; (ii) coordenação dos tributos para abolir a dupla tributação, a eliminação de restrições à criação de empresas e a definição de normas comuns para a criação de instituições financeiras; e (iii) eliminação de barreiras setoriais impostas aos investimentos intra-regionais e nas diferenças na legislação tributária das empresas e das aplicações financeiras. Porém, a criação de um arcabouço jurídico de normas não é condição suficiente para definir os rumos da integração, pois vários outros fatores influem no processo. Por exemplo, a estabilidade política dos países é uma das condições indispensáveis à integração financeira, tornando-se importante à medida que sua falta aumenta os custos da integração.

Embora a importância do fluxo de capitais entre os países do Mercosul seja atualmente inexpressiva, ela poderá vir a crescer no futuro. Caso as políticas monetária e fiscal fiquem inteiramente harmonizadas, e as taxas de câmbio se tornem pouco voláteis, a região adquirirá características de uma área monetária comum, reduzindo-se os diferenciais de taxas de juros e também a importância desses capitais como fator de integração. 
Nessas circunstâncias, os rumos da integração financeira seriam ditados preponderantemente pelos fatores comerciais e pelas taxas de retorno das atividades localizadas nas diferentes áreas.

Deve-se ressaltar ainda que a mobilidade de capitais, com sua característica de volatilidade, tem que ser tratada, necessariamente, como uma variável de caráter cíclico. Em todo caso, trata-se de uma variável cujos efeitos se transmitem velozmente sobre o resto das variáveis econômicas e onde o efeito "contágio" entre mercados financeiros é muito acentuado. As inovações em matéria de engenharia financeira não fazem senão elevar as margens da volatilidade da mobilidade de capitais (Lavagna, 2003).

\subsection{Integração do Mercado de Trabalho no Mercosul}

Com toda a dificuldade dos países do Mercosul quanto à consolidação da união aduaneira, a integração do mercado de trabalho, segundo Rodrigues (1997), é um assunto precipitado para ser discutido em âmbito do Mercosul. Pochmann (2000) relatou que, no contexto de promoção comercial recíproca, o Mercosul como processo de integração sustentável pela redução dos custos domésticos e direcionados para o acesso aos mercados regionais constitui uma realidade distinta da originalmente prevista em momentos históricos anteriores. O processo de integração do Mercosul assenta-se mais nas metas de natureza comercial que na promoção da integração do mercado de trabalho inter-regional.

Esse perfil de concentração nas relações comerciais do Mercosul, amparado pelo movimento global de desregulamentação financeira, direcionou uma atenção cada vez menor ao mercado de trabalho do Mercosul. Somado a isso, Pochmann (2000) afirmou que é inerente às economias dos países do Mercosul um processo de desestruturação do mercado de trabalho interno, por onde ocorrem (i) a ampliação do desemprego, (ii) a redução na participação relativa do emprego assalariado no total da ocupação e (iii) a geração de ocupações precárias. 
A experiência européia tem demonstrado que, por mais que se estimule a mobilidade de trabalho entre países, ela acaba por não ocorrer de acordo com o efeito estabelecido por Mundell. Somado a isso, observa-se a existência de riscos potenciais (como desemprego e deterioração nas condições de emprego do país receptor) decorrentes da instalação da zona livre de circulação de trabalhadores entre países com nítidas assimetrias sociais, como ocorre entre os países do Mercosul. De fato, uma grande mobilidade de trabalho entre países, embora resulte em um efeito econômico eficiente, tem em contrapartida um grave efeito social que, no caso dos países do Mercosul, pode prejudicar o processo de integração econômica.

Esses fatos indicam, ao menos no curto prazo, que a liberalização do mercado de trabalho no Mercosul, aos moldes de uma AMO, dificilmente poderá ser atingida, diante das assimetrias sociais vividas pelos países integrantes. Um processo racional de integração do mercado de trabalho no Mercosul deverá passar por alguma regulamentação, ao menos no curto prazo, antes que haja uma completa liberalização no bloco.

É importante ressaltar, no entanto, que a literatura econômica mostra que a mobilidade de trabalho pode ser devidamente substituída entre países com relações comerciais. Krugman e Obstfeld (2000) explicaram que o comércio pode servir como alternativa à mobilidade de fatores. Para que isso ocorra, o país local deve exportar bens intensivos em trabalho que produz e importa bens intensivos em capital que não produza eficientemente. É possível que tal comércio leve à equalização dos preços dos fatores capital e trabalho; caso isso ocorra, eliminar-se-ia, naturalmente, o incentivo à mobilidade do trabalho. A idéia básica é de que a mobilidade dos fatores, em termos econômicos, é similar ao comércio de bens. Ambos ocorrem pelos mesmos motivos e produzem resultados semelhantes.

Portanto, a integração comercial corrobora a hipótese de Mundell de que a intensa mobilidade de trabalho não é um requisito rígido à unificação monetária. Em outras palavras, mesmo na ausência de uma forte imigração 
entre os países, ainda é possível o surgimento de uma única moeda entre eles, através de vínculos comerciais.

\section{Metodologia}

A metodologia aqui apresentada teve por objetivo principal investigar em que estágio de integração o Mercosul se encontra, segundo os critérios de uma AMO. Pretendeu-se, assim, avaliar a distância que o bloco se encontra de uma união monetária, verificando os ganhos e as perdas que uma unificação monetária traria aos países que o compõem.

São inicialmente realizadas análises gráficas para se avaliar uma possível convergência dos indicadores macroeconômicos indicados pelo Tratado de Maasticht, indispensáveis para uma integração monetária sólida. Entre Brasil e Argentina serão analisados o percentual da dívida pública em razão do PIB, o percentual das necessidades de financiamento do setor público em razão do PIB, as taxas de juros e os índices de inflação. Também será analisado o movimento comercial entre os dois países, igualmente importante para uma união econômica.

Será implementada, ainda, uma análise da ocorrência de choques nas economias do Brasil e da Argentina. Para esse fim, serão utilizadas análises gráficas e de correlação entre as variáveis especificadas. Para se estudar a simetria de choques internos entre os dois países, foram escolhidas três variáveis: o produto interno bruto (PIB), a utilização da capacidade instalada da indústria e o percentual de desemprego. A variação do PIB revela os choques internos que têm ocorrido nos países em determinado período de tempo. Essas análises serão realizadas utilizandose dados trimestrais. Porém, além dessa simetria, interessa saber o efeito que tais choques têm causado em cada economia. Para saber o impacto que os ciclos econômicos têm tido sobre o Brasil e Argentina, escolheramse como variáveis de análises a taxa de desemprego aberta e a utilização da capacidade instalada das indústrias. Finalmente, baseado em Carneiro (2002), será elaborado um gráfico de tendência de AMO, considerando- 
se os benefícios e custos relativos à implementação de uma unificação monetária no Mercosul.

Os dados utilizados foram obtidos no banco de dados do Instituo de Pesquisa Econômica Aplicada (IPEADATA), no Instituto Brasileiro de Geografia e Estatística (IBGE), no Instituto Nacional de Estatística y Censo da Argentina (INDEC) e no Ministério de Economia Argentina (MECON) e referem-se ao período de 1990 a 2003. Foram usados dados de PIB, das exportações totais mensais, da dívida total sobre o PIB, das necessidades de financiamento do setor público sobre o PIB, das taxas de juros internas, do desemprego aberto e do percentual da utilização da capacidade instalada da indústria de cada país.

\section{Resultados e discussão}

\subsection{Análise Gráfica de Indicadores Macroeconômicos}

Na Figura 1, apresenta-se a dívida total líquida como percentual do PIB e indica-se que tanto o Brasil quanto a Argentina acumularam uma dívida externa que, até o primeiro trimestre de 1999, não havia ultrapassado $40 \%$ do PIB. Os seguidos aumentos da dívida total brasileira, após esse período, podem ser creditados às sucessivas desvalorizações cambiais, tendo o máximo dessa dívida como proporção do PIB chegado, ao terceiro trimestre de 2002, a um total de $63 \%$ do PIB.

Sabe-se, no entanto, que uma grande parcela da dívida total argentina está atrelada ao dólar. Como mencionado, o aumento de sua dívida foi necessário para a manutenção da currency board, e, por conseqüência, a desvalorização de sua moeda, após janeiro de 2002, fez que a dívida do país atingisse $140 \%$ do seu PIB total a partir do segundo trimestre de 2002, levando-o a decretar moratória. 
Uma comparação entre os dois países evidencia que, até 2002, Brasil e Argentina apresentavam um padrão de dívida muito semelhante, o que contribuiria para a convergência de políticas econômicas entre ambos. Contudo, observou-se que, após 2002, o comportamento da dívida total, resultado da recente crise argentina, impossibilitou tomadas de decisões políticas comuns entre os dois países. Dada a forte divergência observada após o primeiro trimestre de 2002, existe agora um impasse na convergência macroeconômica e na ampliação da integração econômica entre Brasil e Argentina.

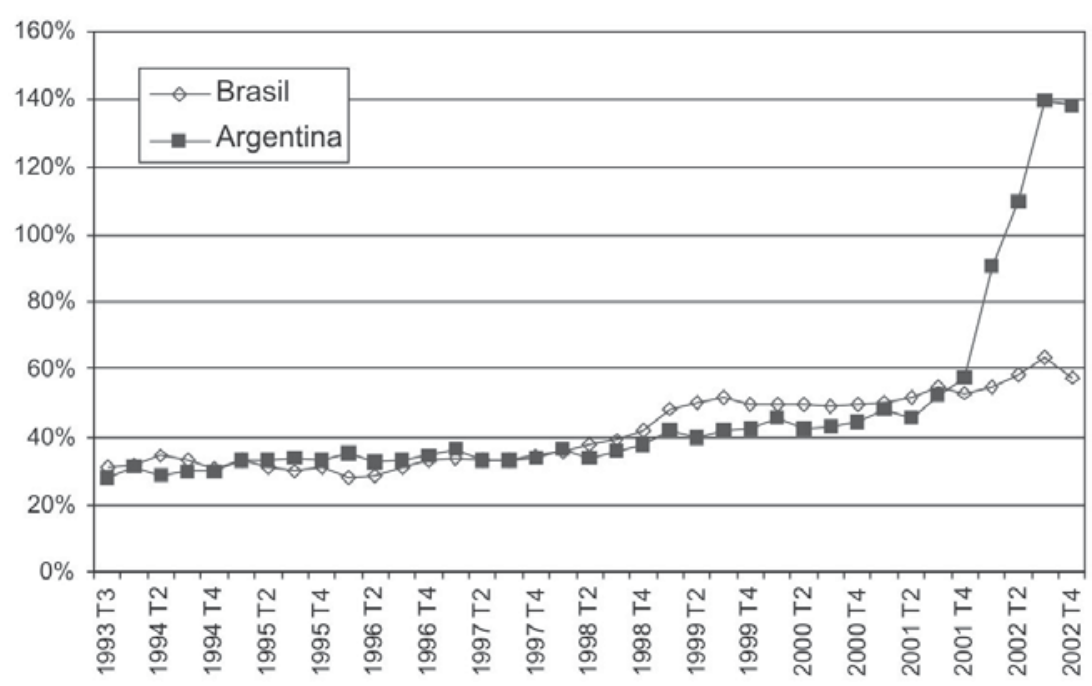

Fonte: Brasil, IPEA (2003); Argentina, MECON (2003).

Figura 1 - Percentagem da dívida total líquida sobre o PIB do Brasil e da Argentina, dados trimestrais - 1993:3 a 2002:4.

$\mathrm{Na}$ Figura 2, relaciona-se a necessidade de financiamento do setor público (NFSP), conceito primário ${ }^{5}$, como percentual do PIB, em dados trimestrais de 1994 a 2003. Nota-se nitidamente, nessa figura, que não há nenhuma tendência de convergência desse indicador econômico entre os dois

A necessidade de financiamento do setor público é definida como as despesas menos as receitas do setor público; sinal positivo indica déficit e negativo, superávit. O conceito primário relaciona-se aos gastos do governo não relacionados à dívida interna. 
países. As contas públicas internas da Argentina têm apresentando oscilações de déficits e superávits, variando, em média, em torno de -1 a $1 \%$, o que não sinaliza uma forte austeridade fiscal da Argentina. O Brasil, no entanto, após o quarto trimestre de 1998 tem acumulado sucessivos superávits, apresentando, em média, uma necessidade de financiamento negativa entre -3 e $-5 \%$ do PIB, sinalizando, assim, uma forte preocupação do governo brasileiro com os resultados de longo prazo. Dessa forma, a Figura 2 indica também uma forte divergência de políticas econômicas fiscais entre os dois países. Essa divergência da NFSP entre os dois países deve ser uma preocupação adicional para com o futuro da integração econômica entre Brasil e Argentina.

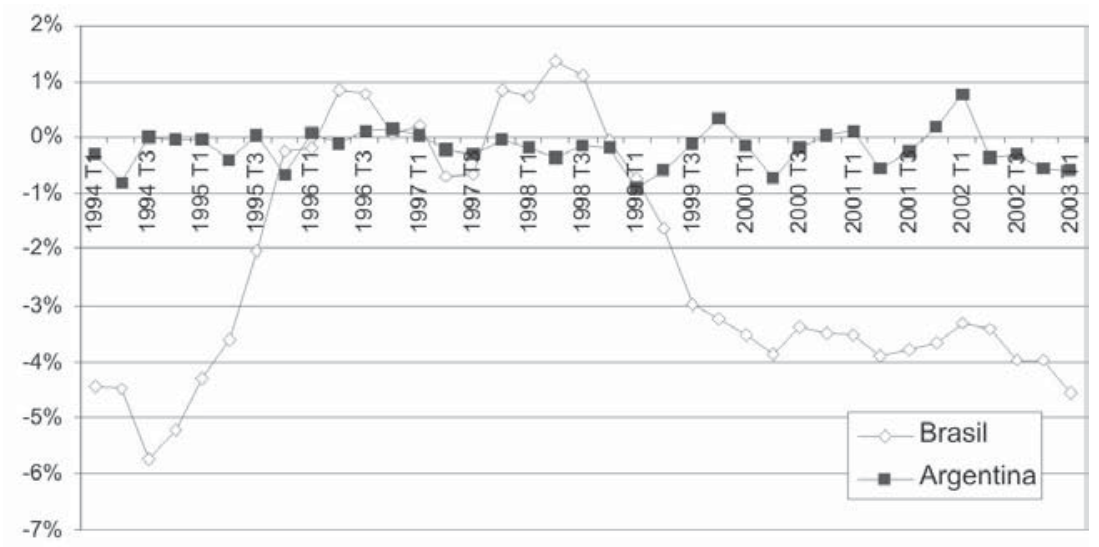

Nota: conceito primário refere-se às despesas menos receitas sem incluir o pagamento de juros Fonte: Brasil, IPEA (2003); Argentina, MECON (2003)

Figura 2 - Necessidade de financiamento do setor público como percentual do PIB do Brasil e da Argentina (conceito primário), dados trimestrais de 1994:1 a 2003:1.

Os dados apontaram que o Brasil tem controlado melhor sua dívida, apresentando constantes superávits primários. Assim, depende dele mesmo para melhorar seus resultados fiscais. Ao que parece, a consolidação das contas internas brasileiras está associada à atual 
austeridade fiscal. A Argentina, entretanto, além de ter que aumentar a sua austeridade fiscal, depende ainda da cotação de sua moeda diante do dólar. Hoje, o principal instrumento utilizado por esse país no controle de sua dívida consiste na negociação com os credores internacionais, o que tem gerado resultados positivos para sua economia.

Na Figura 3 são observadas as taxas de juros praticadas nos dois países. Nesse período, com dados mensais de janeiro de 1996 a maio de 2003, podem ser verificadas três fortes variações da taxa de juros brasileira: a primeira, ocorrida em novembro de 1997, em resposta à "crise" asiática; a segunda, iniciada em setembro de 1998, em resposta à "crise" russa; e a terceira, em fevereiro e março de 1999, em face da desvalorização do real. Na Argentina, o registro de grandes picos na taxa de juros passaram a ocorrer mais recentemente, com a primeira grande elevação em julho de 2001, que passou de 10 para $21 \%$ até atingir o auge em julho de 2002 (76\%). Todas essas elevações observadas nos dois países foram realizadas para estancar fluxos de saída de capitais e defender a taxa cambial. Em períodos de normalidade das economias, a taxa de juros tem sido o principal instrumento de combate à inflação. Tanto no Brasil quanto na Argentina, após o abandono do câmbio fixo, a taxa de juros tornou-se a âncora nominal para a inflação, o que tem gerado uma tendência de convergência dos juros entre os dois países. Todavia, a utilização da taxa de juros como âncora nominal da inflação não está isenta de custos para essas economias. Como se sabe, altas taxas de juros limitam o crescimento econômico, ao aumentar o custo do crédito e ao afetar negativamente as expectativas de crescimento dos empresários, além de aumentarem a dívida pública, uma vez que esta é formada predominantemente por títulos indexados à taxa de juros e à taxa de câmbio. 


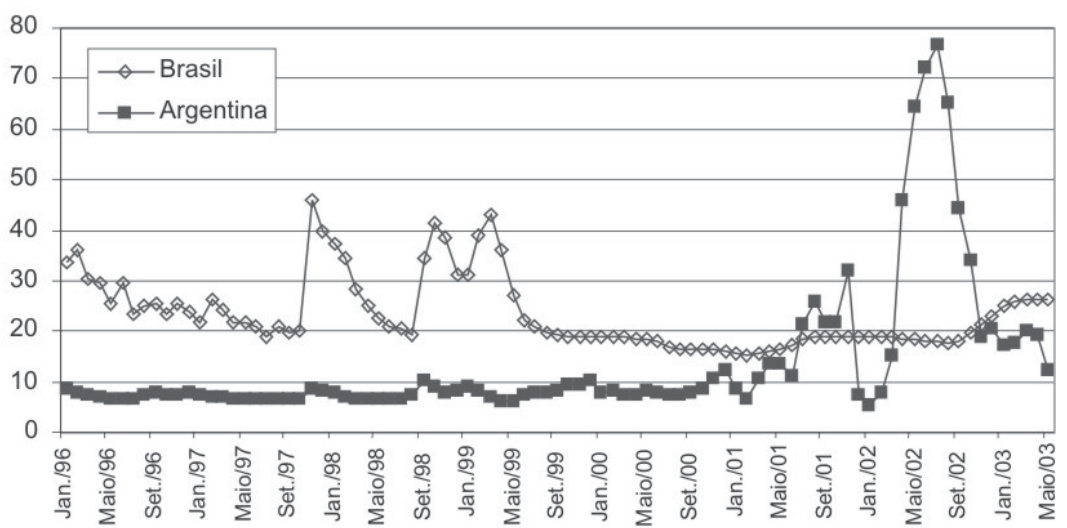

Fonte: Brasil - Taxa de juros - Selic, IPEA (2003); Argentina - Depósitos em pesos a prazo fixo, 30 a 59 d., MECON (2003).

Figura 3 - Taxa de juros entre Brasil e Argentina, anualizada (\% a.a.).

Dados mensais - 2001:1 a 2003:5.

Na Figura 4, apresenta-se a taxa de inflação mensal de Brasil e Argentina, entre 2000 e 2003, período em que é possível verificar uma forte austeridade monetária das duas economias. Porém, entre janeiro e outubro de 2002 visualiza-se uma substancial elevação das taxas de inflação da Argentina, que ultrapassaram 10\% a.m., em maio de 2002. Embora se observe uma grande elevação das taxas de juros argentinos nesse mesmo período, o confisco bancário anunciado pelo governo, associado à escassez de produtos causada pela crise, gerou uma grande pressão inflacionária. Todavia, após a superação da fase mais crítica da crise, a economia argentina novamente passou a vislumbrar baixas taxas de inflação. $\mathrm{O}$ Brasil, por sua vez, não demonstrou, durante esse período, grandes choques inflacionários, e sua taxa média de inflação atingiu o máximo de 3,5\% a.m., com expectativa de uma inflação anual em torno de 11 a $13 \%$. 


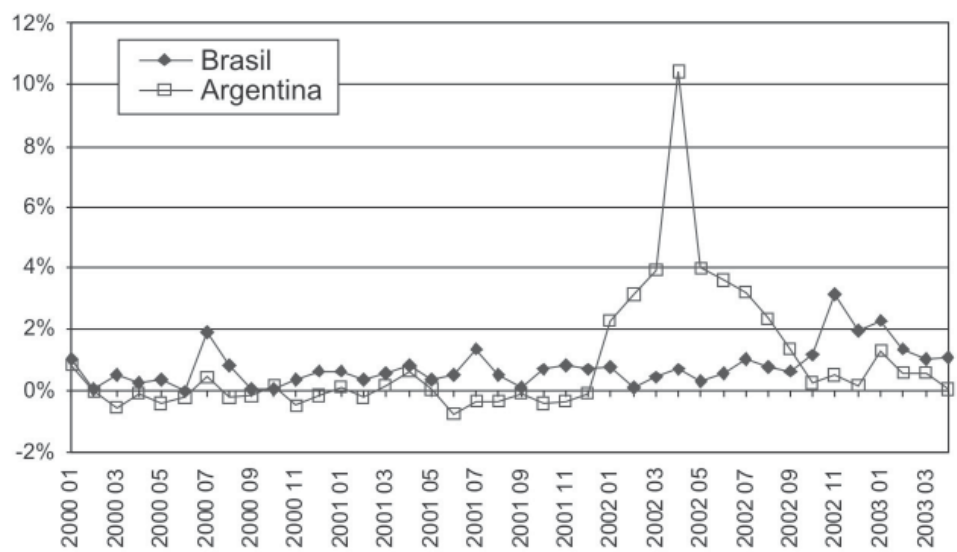

Fonte: IPEA

Figura 4 - Taxa de inflação (IPC) do Brasil e da Argentina. Índices mensais - 2000:1 a 2003:4.

No decorrer da integração econômica entre Brasil e Argentina, o primeiro grande impasse estava ligado à diferença das políticas cambiais adotadas entre eles. Com a desvalorização e a adoção de uma taxa flexível de câmbio da moeda argentina em 2002, o novo obstáculo foi com relação às contas públicas, especificamente ao estrondoso aumento da dívida total argentina.

Embora se verifique que a dívida/PIB e a NFSP/PIB tenham forte divergência, entre os dois países, a taxa de juros e a taxa de inflação têm apresentado tendências convergentes, diante da similaridade das políticas monetárias que Brasil e Argentina têm adotado. Todavia, a possível convergência da taxa de juros e da inflação é decorrente de metas de políticas internas dos dois países de defesa do câmbio e de baixa inflação e não de uma política consistente direcionada à unificação monetária do bloco Mercosul. Porém, isso deve ser reconhecido como fator positivo para a integração monetária no longo prazo, já que uma baixa inflação associada a uma estabilidade cambial são fatores imprescindíveis para um processo de unificação monetária coerente. Dessa forma, espera-se que, à medida que essas políticas se tornem mais rígidas, vislumbre-se o 
aumento da convergência da taxa de juros e da taxa de inflação, podendo se realizar no futuro até mesmo metas de políticas econômicas conjuntas em direção à integração monetária.

Espera-se que, no longo prazo, Brasil e Argentina obtenham a convergência desses indicadores macroeconômicos selecionados e que alcancem as condições necessárias para aprofundamento da integração comercial e, no limite, a adoção de uma única moeda.

\subsection{Análise Gráfica da Simetria de Choques}

Uma análise das variações trimestrais do PIB entre Argentina e Brasil, observada na Figura 5, revelou que, no período entre o primeiro trimestre de 1993 e o quarto de 2002, apesar de não haver igualdade nas variações percentuais, tanto Brasil quanto Argentina tiveram variações simétricas em suas economias. Após o segundo trimestre de 2001, no entanto, a diferença entre eles se tornou bastante acentuada.

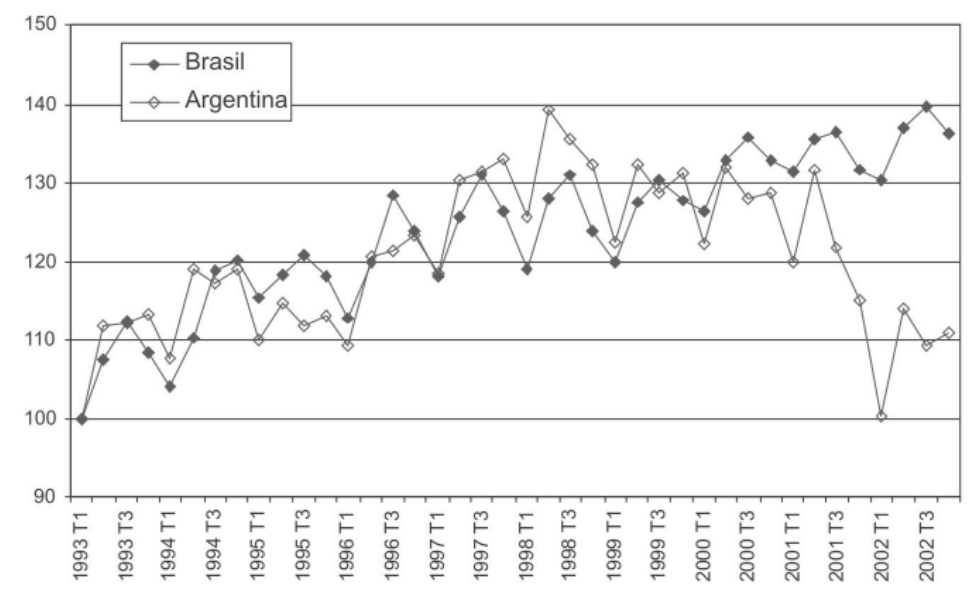

Fonte: Brasil - PIB a preços de mercado, IPEA (2003); Argentina - PIB a preços de mercado, INDEC (2003)

Figura 5 - Índice do PIB do Brasil e da Argentina. Dados trimestrais 1993:1 a 2002:4 (1993:1=100). 
A correlação entre esses choques aponta que cerca de $46 \%$ das variações dos PIBs brasileiros e argentinos ocorreram simultaneamente. Porém, observou-se que a diferença se tornou mais divergente após o primeiro trimestre de 2001. Uma análise de correlação aplicada até esse período indicou que o nível de correlação entre as duas variáveis era de $82 \%$. Em média, os dois países cresceram e entraram em recessão juntos, porém em percentagens diferentes; até o período antecedente à crise argentina, havia uma boa regularidade entre os ciclos econômicos de Brasil e Argentina.

Na Figura 6, apresenta-se uma análise adicional realizada com dados mensais de utilização da capacidade instalada da indústria, visando verificar o efeito que as crises têm sobre as economias estudadas, observando-se também sua capacidade de recuperação.

Os dados indicaram que, após o ano de 1999, os ciclos econômicos têm causado impactos mais fortes na economia argentina que na brasileira e, ainda, as fases de expansão da economia argentina não têm sido capazes de alavancar a produção, deixando que grande parte de sua capacidade industrial fique ociosa. Observou-se que até 1999 havia certa simetria da utilização da capacidade industrial desses países, cerca de 45\%. Porém, após esse ano, surge um completo descompasso entre a capacidade instalada brasileira e argentina. 


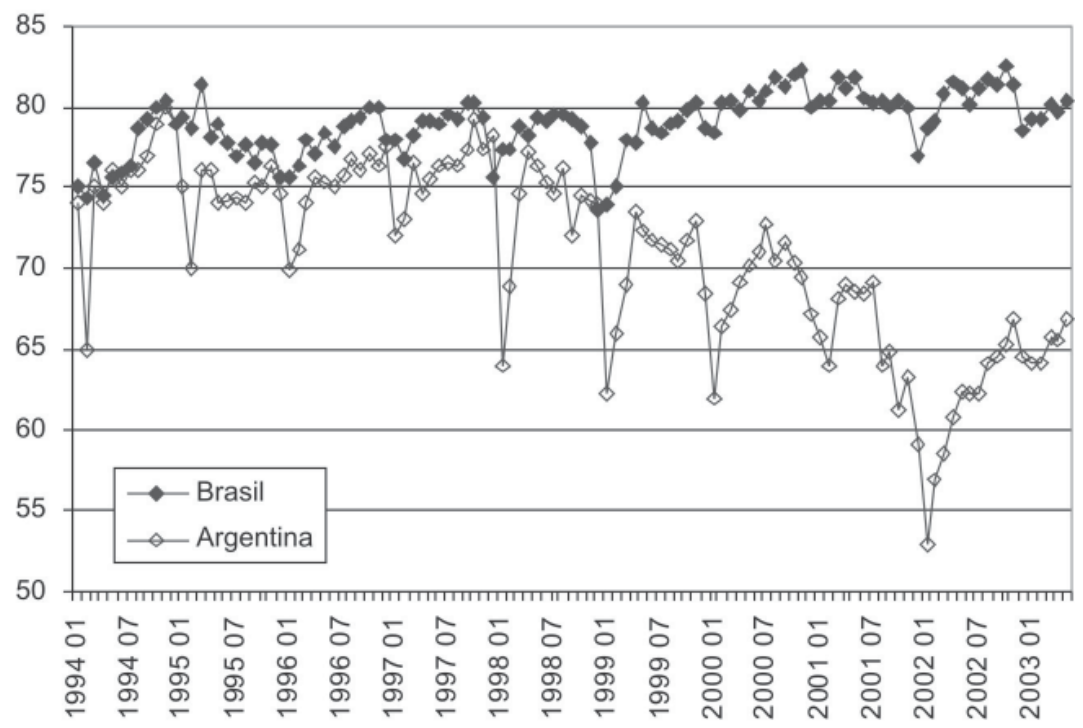

Fonte: Brasil - IPEA, (2003); Argentina - MECON (2003)

Figura 6 - Percentagem da utilização da capacidade instalada da indústria do Brasil e da Argentina. Dados mensais - 1994:1 a 2003:5.

As taxas de desemprego aberto entre Brasil e Argentina, mostrada na Figura 7, também evidenciaram a existência de um descompasso dos impactos de choques econômicos sobre as duas economias. As variáveis apresentadas indicam que, desde 1993, a Argentina tem tido um crescente aumento do desemprego, que varia de 5 até $22 \%$, enquanto o Brasil tem mantido uma faixa mais estável de variação, em torno de 5 a 10\%. Esses resultados indicam que os custos da coordenação macroeconômica entre Brasil e Argentina podem ser extremamente altos, já que em uma área monetária as decisões de políticas econômicas devem ser uniformes. 


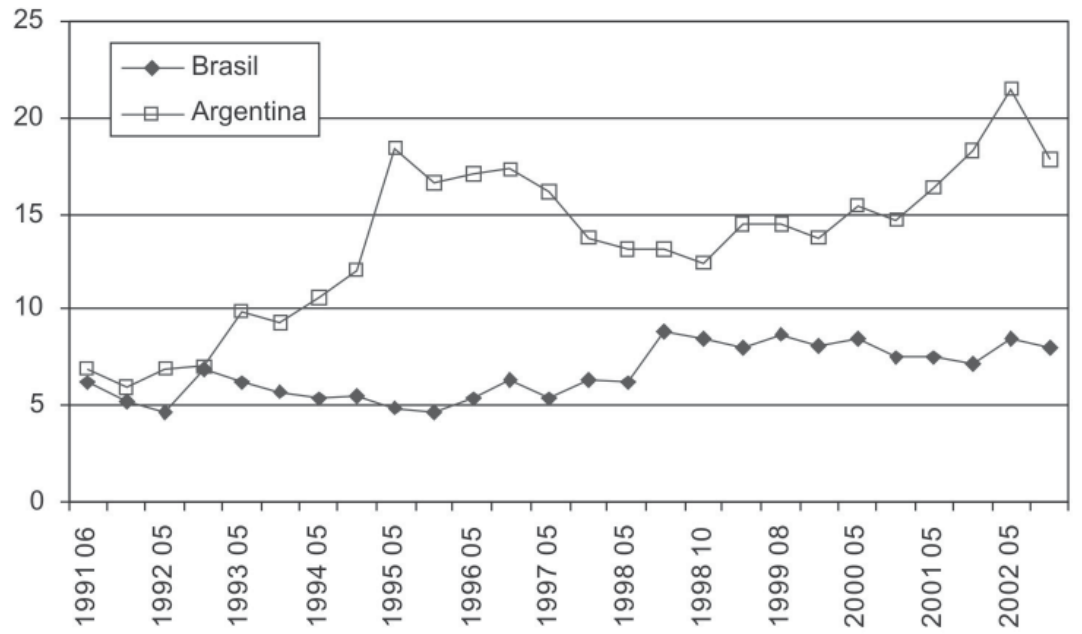

Fonte: Brasil - IBGE (2003); Argentina - IPEA (2003)

Figura 7 - Taxa de desemprego aberto como percentual da população do Brasil e da Argentina. Índices semestrais e trimestrais 1991:6 a 2002:9.

\subsection{Benefícios e Custos de uma AMO entre Brasil e Argentina}

Baseado em Carneiro (2002), elaborou-se a Figura 8, comparando os benefícios e os custos que uma união monetária poderia trazer. Adicionalmente, essa figura indica se houve alguma tendência de formação de AMO entre os dois países no decorrer da evolução do Mercosul.

O eixo vertical mede o benefício adquirido com uma possível união monetária entre os dois países e a corrente de comércio (exportações mais importações) sobre o PIB total de ambos. Nesse sentido, quanto maior o percentual da corrente de comércio em relação ao PIB total, maior o ganho adquirido de uma união monetária entre Brasil e Argentina. 
O eixo horizontal representa o diferencial entre o percentual do desemprego brasileiro e argentino, em módulo, indicando, assim, o custo de uma coordenação macroeconômica entre os dois países. Entende-se que, quanto maior for a disparidade das taxas de desemprego, maior será o custo de implantação de uma única moeda entre os dois países.

A Figura 8 indica que os anos concentrados no quadrante superior à direita são aqueles em que havia maior tendência de formação de uma AMO. No entanto, os dados indicam que não há uma tendência consistente, ano após ano, direcionado à formação de uma AMO entre Brasil e Argentina. Nota-se que nos anos iniciais de formação do bloco Mercosul, entre 1991 até 1994, indicados pela seta 1, Brasil e Argentina apresentaram tendência de crescimento do comércio e aumento de custos. Em 1991, o bloco apresentava um baixo custo de unificação, mas se tornou crescente até 1995.

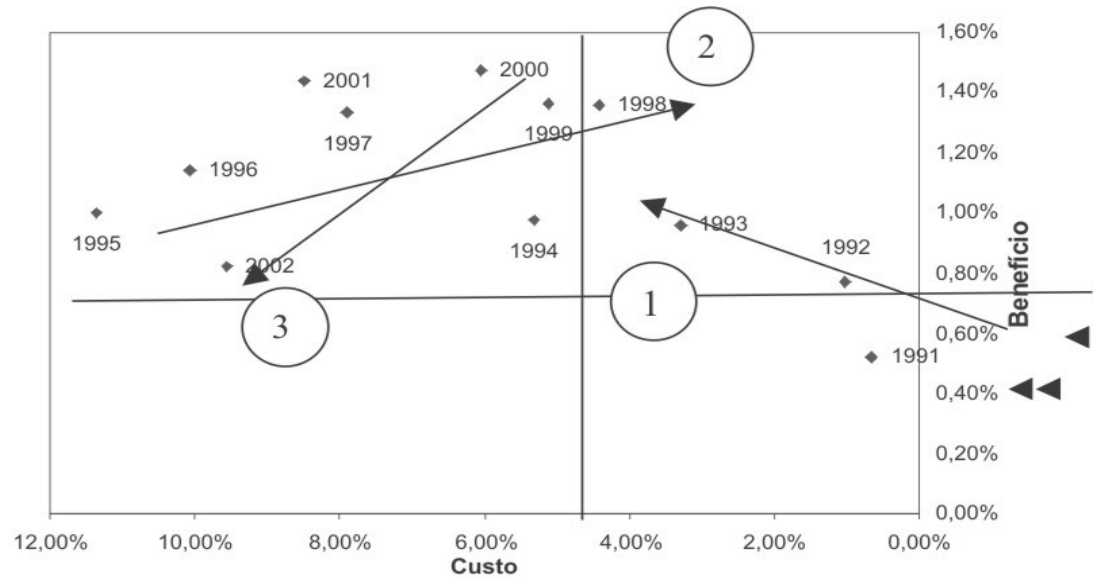

Fonte: Elaboração dos autores baseada em Carneiro (2002). Dados anuais.

Figuras 8 - Níveis de tendência de AMO entre Brasil e Argentina, entre 1991 e 2002.

A seta 2 na figura indica que a partir de 1995 há uma tendência consistente de formação de AMO, em que os custos diminuem e os benefícios aumentam. Entre 1995 e 1998, ano a ano houve crescimento das relações comerciais e uma aproximação das taxas de desemprego. Isso pode ser 
creditado pelo sucesso inicial dos programas de estabilização, que mantiveram a paridade cambial, estabilizando as taxas de inflação, além do contínuo processo de desgravação tributária e formação da TEC. O ano de 1998 foi o ano em que os dois países mais se aproximaram de uma AMO.

A seta 3 marca o fim das altas taxas de crescimento comercial, além de apontar o aumento dos custos de integração econômica. Esse período se inicia em 1999, momento no qual o Brasil abandona a paridade cambial, e a Argentina começa a sofrer os primeiros sinais da atual crise. Dessa forma, no que diz respeito aos ganhos de formação de uma AMO, observou-se que, no período entre 2000 e 2003, houve afastamento da tendência de formação de AMO, pois os benefícios diminuem e os custos aumentam consideravelmente. No ano de 2002, o percentual de comércio entre os dois países voltou ao mesmo nível de 1992.

A teoria de AMO ensina que a adoção de uma única moeda por um conjunto de países se torna ótima a partir do momento em que as vantagens obtidas superam os custos adicionais da união monetária. Porém, o que se verificou graficamente é que, no momento, nem Brasil nem Argentina se beneficiariam, em termos comerciais, de uma única moeda no Mercosul. Os dados evidenciam que o atual nível de comércio entre eles não funciona como um bom estabilizador para essas economias.

\section{Conclusões}

As bases que sustentam o Mercosul são ainda fracas, comparando-se com a UE, e necessitam se tornarem mais sólidas, para que um dia prevaleça de fato um mercado comum, como é a proposta atual do bloco.

Inicialmente, este trabalho verificou o comportamento de variáveis que são consideradas relevantes para uma unificação monetária e que devem ser convergentes entre países que se propõem a uma integração econômica. As análises realizadas sobre a dívida pública e o déficit público 
indicaram uma forte divergência entre Brasil e Argentina. Há fortes evidências de que essa situação está associada ao afastamento das políticas fiscais e monetárias que foram implementadas nos dois países ao longo da década de 1990. Os problemas de conjuntura por que passaram foram diferentes, impossibilitando, no curto prazo, tomadas de decisões únicas em direção à unificação monetária. No entanto, as atuais políticas monetárias adotadas por Brasil e Argentina têm apontado alguma tendência para convergência da taxa de juros e da taxa de inflação. Assim, os indicadores têm apontado para uma forte divergência de políticas fiscais e uma tendência de convergência de políticas monetárias.

As análises de choques internos apresentaram simetria nas variações do PIB dos dois países. No entanto, demonstrou-se que os efeitos das recessões têm sido mais perversos na Argentina do que no Brasil, haja vista que há uma grande distância, em favor do Brasil, do percentual de utilização da capacidade instalada das indústrias e dos índices de desemprego. Essa distância de indicadores aponta um alto custo para a viabilização de políticas monetárias comuns entre os dois países.

O volume de comércio realizado entre os países tem apresentado tendências declinantes desde 1998. Portanto, para uma AMO na qual o comércio deve existir como fonte de estabilização e ganho monetário, o Mercosul não atinge ainda a característica de integração comercial necessária para a formação de uma área monetária.

As análises sobre benefícios e custos de uma única moeda no Mercosul indicaram que, desde 1998, os custos têm aumentado, enquanto os benefícios, diminuído, com o bloco tendo retrocedido no que tange às hipóteses de área monetária. Os sucessivos choques que recaem sobre as economias estudadas têm afetado negativamente a formação de uma área monetária. Até 1998, quando os dois países tiveram uma similaridade em políticas cambiais e monetárias, o Mercosul cresceu a largos passos, aumentando sua integração comercial. No entanto, os sucessivos choques, após 1998, têm prejudicado a continuação do desenvolvimento do bloco, tendo recentemente, no ano de 2002, o Mercosul regredido comercialmente ao patamar do início de sua criação, em 1992. 


\section{Referências}

BID-INTAL. Informe Mercosul, Buenos Aires, n.1, p.80, Jul.-Dez. 1996.

CARNEIRO, D.D. Sobre a unificação monetária do Mercosul. Carta Econômica Galanto, n. 27/2 p. 25, Fev. 2002. Disponível em: $<$ www.econ.puc-rio.br/Dionisio/galantopdf $>$.

EICHENGREEN, B. European monetary unification - Theory, practice and analysis. Cambridge: The MIT Press, 1998. 349 p.

EICHENGREEN, B. International monetary arrangements for the $21^{\text {st }}$ century. Washington: Brookings Institution, D.C., 1994.

FRANKEL, J. No Single currency regime is right for all countries or at all times. [S.1.]: NBER Set. 1999. (Working Paper, n 7339).

GIAMBIAGI, F.; RIGOLON, F. Áreas monetárias ótimas: teoria,unificação monetária européia e aplicações para o Mercosul. Economia Aplicada, São Paulo, v.3, n.1, p 79-108, 1999.

GIAVAZZI, F.; PAGANO, M. The advantages of tying one's hands: e m s discipline and Central Bank Credibility. European Economic Review, n.32, p. 82-1055, 1988.

IBGE - Instituto Brasileiro de Geografia e Estatística. Disponível em: <www.ibge.gov.br>. Acesso em: 15 Nov. 2003.

INDEC - Instituto de Estadísdica y Censos. Disponível em: <www.indec.gov.ar>. Acesso em: 15 Nov. 2003.

IPEA - Instituto de Pesquisa Econômica Aplicada. Disponível em: <www.ipeadata.gov.br>. Acesso em: 15 Nov. 2003. 
KRUGMAN, P.; OBSTFELD, M. Economia Internacional - Teoria e política. 5. ed. São Paulo: Makron Books, 2000. 797 p.

LAVAGNA, R. Mercosul integração e gestão de crises financeiras. Revista Brasileira de Comércio Exterior, n. 63, 2003. Disponível em: <www.funcex.com.br>.

MACHADO, M. F. A Integração financeira do Mercosul. In: BRANDÃO, A.S.; PEREIRA, L.V. (Orgs.). Mercosul: perspectivas de integração. 2. ed. Rio de Janeiro: Editora da Fundação Getúlio Vargas, 1997. p.227-244.

MECON - Ministerio de Economía y Producion. Disponível em: <www.mecon.gov.ar〉. Acesso em: 15 Nov. 2003.

MUNDELL, R. A theory of optimum currency areas. American Economic Review, p.657-65, 1961.

POCHMANN M. Mercosul, competitividade e globalização. In: LIMA, M. C.; MEDEIROS, M. A. (Orgs.). O Mercosul no limiar do século XXI. São Paulo: Cortez, 2000. p. 120-135.

RODRIGUES, M.C.P. O mercado de trabalho e a integração viável. In: BRANDÃO A.S.; PEREIRA, L.V. (Orgs.). Mercosul: perspectivas de integração. 2. ed. Rio de Janeiro: Editora da Fundação Getúlio Vargas, 1997. p.245-270. 


\begin{abstract}
This paper presents the theoretical and empirical aspects of a monetary union between Brazil and Argentina based on the concept of Optimal Monetary Union. The behavior of some Brazilian and Argentinean macroeconomic indicators such as total debt, public deficit, interest rate and inflation rate have been analyzed. Symmetry analysis of economic cycles between these two countries was also done. Most Brazilian and Argentinean macroeconomic indicators have been divergent, probably due to the different monetary and exchange rate policies adopted by these two countries during the 90's.The commercial integration analysis between Brazil and Argentina had detected a low level of commercial integration. Results also suggest that since 1998 there has been a divergent trend of a monetary area formation between these two countries. In other words, in the short run there has been high costs and low benefits associated to a single currency in Mercosur.
\end{abstract}

Keywords: Mercosur, Open Macroeconomics, Optimal Monetary Area, Monetary Union. 
REVISTA DE ECONOMIA E AGRONEGÓCIO, VOL.3, $N^{o} 3$ 